${ }^{8}$ Hakstian, R W, Fournal of Bone and foint Surgery, 1968, 50-A, 1178.

${ }^{9}$ Wynn Parry, C B, and Salter, M, The Hand, 1976, 8, 250.

10 Jabaley, M E, et al, fournal of Hand Surgery, 1976, 1, 119.

11 Donoso, R, Ballantyne, J P, and Hansen, S, fournal of Neurology, Neurosurgery, and Psychiatry, 1979, 42, 97.

12 Bora, F W, fournal of Bone and foint Surgery, 1967, 49-A, 659.

${ }^{13}$ Grabb, W C, et al, Plastic and Reconstructive Surgery, 1970, 46, 31.

${ }^{14}$ Cabaud, $\mathrm{H}$ E, et al, fournal of Hand Surgery, 1976, 1, 131.

15 Bora, F W, Pleasure, D E, and Didizian, N A, fournal of Hand Surgery, 1976, 1, 138.

${ }^{16}$ Millesi, H, Meiss1, G, and Berger, A, fournal of Bone and foint Surgery, 1976, 58-A, 209

17 Sunderland, S, 1979, personal communication.

${ }^{18}$ Millesi, H, Workshop on Peripheral Nerve Injury, 3rd Congress of the International Rehabilitation Medical Association, Basle. International Rehabilitation Medical Association, 1978.

\section{Cystic fibrosis in adults}

Cystic fibrosis is the commonest semilethal genetic disorder in Caucasians. Its gene frequency is about $1: 20$ and it is transmitted as an autosomal recessive trait. Thus roughly one in every 2000 children is born with the disease, girls and boys in equal numbers. The disease is less common in blacks and mongoloid people.

The biochemical sequence that leads to widespread dysfunction of exocrine glands has yet to be determined. Bronchopulmonary disease associated with intractable infection remains responsible for most of the illness and death: the death rate has fallen greatly since cystic fibrosis was first described by Dorothy Anderson 40 years ago, ${ }^{1}$ so that mean survival has increased to more than 15 years from diagnosis. This improvement, which is due to earlier diagnosis and better management in special units, has led to increasing numbers of adolescents and adults with differing degrees of lung disease, pancreatic dysfunction, and other manifestations of cystic fibrosis.

Cystic fibrosis in adults has been the subject of an extensive review of 307 cases of published accounts by di Sant' Agnese and Davis, ${ }^{2}$ comprising 75 of their own cases, all over 18 years of age, and 232 further patients from North America, ${ }^{3}$ Britain, ${ }^{4}$ and Australia. ${ }^{5}$ They also included another 86 cases which emphasised certain aspects of the disease. As in children, in adults bronchopulmonary disease dominates the clinical picture, though there are fewer symptoms of intestinal malabsorption. This progressive bronchopulmonary disease eventually results in respiratory insufficiency and terminal cardiorespiratory failure.

We still do not know the cause of the changes in the lungs. No clear-cut defect in host resistance has yet been shown, but impairment of the characteristics of mucus flow is presumed to be an important factor in the infection, which can never be eradicated. Mucoid strains of Pseudomonas aeruginosa and Staphylococcus aureus remain the dominant bacterial pathogens, but Haemophilus influenzae and Klebsiella sp are alsoimportant. In the patients reviewed by di Sant' Agnese and Davis bronchopulmonary disease was manifested by clubbing of the fingers, which was almost universal (though hypertrophic pulmonary osteoarthropathy was rare); $60^{\circ}$ o had trivial haemoptyses, but fortunately only $7^{\circ}{ }_{0}$ had massive ones. Spontaneous pneumothorax, sometimes bilateral, affected $16^{\circ}{ }_{0}$. Sinusitis is said to be very common, and nasal polyps were detected in $48^{\circ}{ }_{0}$.

Pancreatic insufficiency was recorded in $95^{\circ}$ of the patients, but the older ones needed little dietary restriction and some seemed to thrive without pancreatic replacement. Although only moderately reducing steatorrhoea, pancreatic extracts may reduce the loss of bile acids and consequently the liability to gallstones. Rarely pancreatic function may be preserved, but these patients may suffer from recurrent acute pancreatitis. Diabetes was relatively uncommon, but glucose intolerance was demonstrated in at least $40 \%$. Intestinal obstruction was recorded in $21^{\circ}$ o of patients. It was usually due to the equivalent of meconium ileus (less commonly to intussusception), the contents of the gut being solid or semi-solid when they should have been fluid. Such changes can be distinguished only by contrast radiography, and, after the lung complications, they present the greatest problems in management and treatment. Fortunately most patients with these features respond to medical measures. Cirrhosis of the liver, often with portal hypertension and cholelithiasis, was recorded in $5^{\circ}$ o and $12^{\circ}{ }_{0}$ of cases respectively.

Ninety-five per cent of males have aspermia due to failure of development of the vas deferens, epididymis, and seminal vesicles. Many pregnancies have been reported in women with cystic fibrosis but they are often associated with permanent deterioration in lung function.

Despite the obvious handicap and emotional and social strains in all four series, adolescent and adult patients with cystic fibrosis not only did well at school and at work but managed to fit in well in their social framework. As cystic fibrosis has become the commonest cause of chronic bronchopulmonary infection under the age of 30 , physicians, especially those in thoracic units, will find this review by di Sant' Agnese and Davis extremely useful for its critical review both of the clinical features in adults and of management and treatment.

${ }^{1}$ Anderson, D H, American Fournal of Diseases of Children, 1938, 56, 344.

2 di Sant' Agnese, P A, and Davis, P B, American Fournal of Medicine, 1979, 66, 121 .

${ }^{3}$ Shwachman, H, Kowalski, M, and Khaw, K-T, Medicine (Baltimore), 1977, 56, 129.

+ Mitchell-Heggs, P, Mearns, M, and Batten, J C, Quarterly fournal of Medicine, 1976, 45, 479.

${ }^{5}$ Gracey, M, and Anderson, C M, Australasian Annals of Medicine, 1969, 18, 91 . 